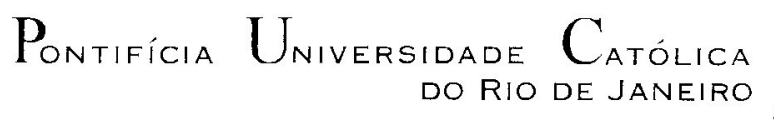

DO RIO DE JANEIRO

Vinicius Jatobá

Aparelhos ideológicos, narrativas do poder

Leituras de Balada da Praia dos Cães

Dissertação de mestrado

Dissertação apresentada como requisito parcial para obtenção do grau de Mestre pelo Programa de Pós-Graduação em Letras da PUC-Rio.

Orientador: Profa. Izabel Margato

Rio de Janeiro

Setembro de 2008 


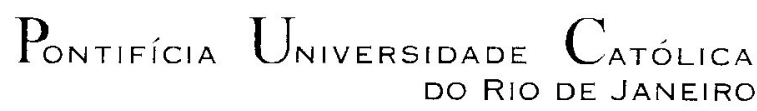

Vinicius Jatobá

\section{Aparelhos ideológicos, narrativas do poder Leituras de Balada da Praia dos Cães}

Dissertação apresentada como requisito parcial para obtenção do grau de Mestre pelo Programa de PósGraduação em Letras da PUC-Rio. Aprovada pela Comissão Examinadora abaixo assinada.

Profa. Izabel Margato Orientadora e Presidente Departamento de Letras - PUC-Rio

Profa. Sílvia Regina Pinto Universidade do Estado do Rio de Janeiro - UERJ

Prof. Ronaldo Menegaz

Departamento de Letras - PUC-Rio

Prof. Paulo Fernando Carneiro de Andrade

Coordenador Setorial do Centro de Teologia

e Ciências Humanas - PUC-Rio

Rio de Janeiro, 8 de setembro de 2008. 
Todos os direitos reservados. É proibida a reprodução total ou parcial do trabalho sem autorização da universidade, da autora e do orientador.

\section{Vinicius Jatobá}

Graduou-se em Ciências Sociais pela UFF (Universidade Federal Fluminense) em 2004.

Ficha catalográfica

Jatobá, Vinicius

Aparelhos ideológicos, narrativas do poder: leituras de Balada da Praia dos Cães / Vinicius Jatobá ; orientador: Izabel Margato. - 2008.

$$
105 \text { f. ; } 30 \mathrm{~cm}
$$

Dissertação (Mestrado em Letras)Pontifícia Universidade Católica do Rio de Janeiro, Rio de Janeiro, 2008.

Inclui bibliografia

1. Letras - Teses. 2. Aparelhos ideológicos de Estado. 3. Ideologia. 4.

Poder omnividente. 5. Romance policial. 6. Trama social de relatos. 7. Pires, José Cardoso. I. Margato, Izabel. II. Pontifícia Universidade Católica do Rio de Janeiro. Departamento de Letras. III. Título.

CDD: 800 
Para meus pais, Antonio e Juçara, e para meu irmão, Vitor, pela amizade incondicional. 


\section{Agradecimentos}

À professora Izabel Margato pelas orientações constantes que ajudaram essa dissertação a encontrar seu devido prumo, e pela fé na realização desse trabalho.

Ao professor Alexandre Montaury pelas discussões sobre a cultura salazarista.

À CNPq pelo apoio sem o qual este trabalho não teria sido realizado.

Ao amigo Marcos Vinicius pelas conversas e discussões fora da sala de aula.

A Cilene Vieira pela amizade e apoio.

As bibliotecas do Centro Cultural Banco do Brasil (CCBB) e Instituto Brasileiro de Medicina de Reabilitação (IBMR) em cujos ambientes acolhedores escrevi essa dissertação. 


\section{Resumo}

Jatobá, Vinicius; Margato, Izabel (Orientadora). Aparelhos ideológicos, narrativas do poder. Leituras de Balada da Praia dos Cães. Rio de Janeiro, 2008. 105p. Dissertação de Mestrado - Departamento de Letras, Pontifícia Universidade Católica do Rio de Janeiro.

Este trabalho tem como objetivo analisar alguns dos mecanismos do poder estatal colocados em cena no romance Balada da Praia dos Cães, de José Cardoso Pires. Partindo das teorias de Louis Althusser sobre os Aparelhos ideológicos de Estado e ensaios de Michel Foucault acerca dos efeitos positivos do poder e da utopia de uma ação omnividente do poder estatal, essa dissertação busca estabelecer alguns pressupostos para uma compreensão holística de alguns mecanismos da construção e manutenção da cultura salazarista, tanto em sua esfera mais institucional quanto na própria intimidade dos sujeitos sociais. A partir de levantamento teórico e leitura de trechos do romance, são trabalhados e analisados aspectos como a construção de ficções de Estado e de uma Economia de Verdade que fazem a gestão da circulação desses relatos, os efeitos paranóicos engendrados na sociedade e no próprio corpo de funcionários do Estado pelo esforço de alcançar a utopia de um poder omnividente e a ação estatal na trama social de relatos.

\section{Palavras-Chave}

Aparelhos ideológicos de Estado, Ideologia, Poder Omnividente, romance policial, trama social de relatos, José Cardoso Pires. 


\section{Abstract}

Jatobá, Vinicius; Margato, Izabel (Advisor). Ideological Apparatuses, State's narratives. Reading Balada da Praia dos Cães. Rio de Janeiro, 2008. 105p. MSc. Dissertation - Departamento de Letras, Pontifícia Universidade Católica do Rio de Janeiro.

This dissertation aims at analysing some mechanisms of state power put into play in the novel Balada da Praia dos Cães, by José Cardoso Pires. Following some theories of Louis Althusser about the Ideological State Apparatuses and Michel Foucault`s essays concerning the positive effects of power and the utopical aim of an omnivident action of state power, this dissertation pursue the construction of some assumptions for an holistic apprehension of some salazarist culture`s mecanisms of construction and maintenance, in its more institutional instance and even on the intimacy of social subjects. Studied and analyzed from a selection of theoretical reading and close reading of novel`s excerpts, aspects as the construction of state fictions and an Economy of Truth that makes the management of the circulation of such fictions, the paranoid outcomes created on society and also into the proper body of State`s employees as a result of the the effort to achieve the utopical omnivident power and the State action into social narrative web.

\section{Keywords}

Ideological State Apparatuses, Ideology, Omnivident Power, police novel, social narrative web, Jose Cardoso Pires. 


\section{Sumário}

1. Introdução

2.1. Aparelhos ideológicos de Estado 13

2.2. O Estado como narrador 24

2.3. Os efeitos positivos do poder 34

3.1. Balada da Praia dos Cães e romance policial 41

3.2. Balada da Praia dos Cães e Estado Paranóico 31

3.3. Balada da Praia dos Cães e detetive como leitor

4.1. Elias como leitor da trama de relatos 66

4.2. O romance dentro do romance [O Lobo do Mar] 79

4.3. A PIDE não aparece nos arquivos

5. Conclusão

102

6. Referências bibliográficas

106 
A era da ordem é o império das ficções, pois não há poder capaz de fundar a ordem somente com a repressão de corpos com corpos. Necessitam-se forças fictícias.

Paul Valéry. 